\title{
Location of Glioblastoma and its Significance in Response to Treatment
}

\author{
Iddo Paldor and Gill E Sviri* \\ Department of Neurosurgery, Israel Institute of Technology Haifa, Israel
}

*Corresponding author: Gill E Sviri, Department of Neurosurgery, Rambam (Maimonides) Health Care Campus, Technion, Israel Institute of Technology, Israel.
Received Date: November 07, 2019

Published Date: November 12, 2019

\begin{abstract}
Recent years have seen progression in the understanding of the pathogenesis, epigenetic and genetic changes in glioblastoma (GB). These characterizations have focused mainly on the prognostic significance and potential targets for therapeutic intervention. However, other traits of these highly malignant tumors have also been discovered as biproducts or as primary areas of research. Both surgery and radiation are less effective in periventricular glioblastoma, perhaps owing to this area being the niche for pluripotent stem cells in glioblastoma. Surgery carries less of a survival benefit in deep seated glioblastoma, in part because gross total resection of these tumors is uncommonly reached. All treatment modalities are less efficacious for multifocal glioblastoma. There is not enough data in the literature about the prognosis and treatment of specific single lobe supratentorial glioblastoma.
\end{abstract}

\section{Introduction}

Recent years have seen progression in the understanding of the pathogenesis, epigenetic and genetic changes in glioblastoma (GB) [1-13]. These characterizations have focused mainly on the prognostic significance and potential targets for therapeutic intervention. However, other traits of these highly malignant tumors have also been discovered as biproducts or as primary areas of research. Among these is differential localization in the central nervous system (CNS), and its significance in prognosis, in pathogenetic pathways and in amenability to different therapies.

\section{Sensitivity of Differently Located Tumors to Treatment Modalities}

\section{Periventricular glioblastoma}

Perhaps the most commonly explored location of GB is the periventricular zone (PVZ). GB in the PVZ has been shown to have significantly better migration and invasion capacities compared to cortical GB, related to down-regulation of the RND-1 [14]. Tumors in this area have been shown to be more likely to employ the MAPK/TSC/mTOR pathway, also bringing about a more aggressive phenotype [15]. Finally, and perhaps most importantly, PVZ glioblastoma have also been shown to contain niches, in which glioblastoma stem cells are in direct contact with the endothel of blood vessels [16-19]. Ventricular and periventricular zone GBs have been shown to have unique molecular and genetic alterations. These alterations have also been shown to translate into poorer survival for these tumors. This is true even when controlled for extent of resection (EOR) and complication rate, suggesting a truly biologically unfavorable tumor, rather than a difference in resectability [20-26].

Radiation treatment is more cumbersome in the periventricular and subventricular zones. It has been shown that radiation doses over 54Gy do not improve, and may potentially worsen prognosis when given to GB in the periventricular zone [27]. Whether this represents increased sensitivity of the area to radiation treatment or saturation of the sensitivity of GB in this area to radiation (related to their stem cell potential, discussed earlier), is unclear.

\section{Basal ganglia and thalamus glioblastoma}

Deep seated glioblastoma - tumors in the basal ganglia, insula and thalamus, have been shown to carry a worse prognosis as compared to glioblastoma in other locations [22,28,29]. However, extent of resection, a known predictor of outcome in glioblastoma, has also been shown to be significantly lower in deep seated glioblastomas [30-33]. It is unclear whether the worse prognosis is merely a representation of the lesser extent of resection or an actual survival difference. There has been no direct assessment of 
the efficacy of radiation for treatment of deep seated glioblastoma compared to GB in other locations.

\section{Multifocal glioblastoma}

There is some evidence to show that multifocal glioblastoma are not only variable in location, but that the different tumors in the same patient may, in fact, carry different pathways [34,35]. However, the monoclonal origin of the different tumors in the same patient has also been shown. [36,37]. Molecular and intracellular pathways are not the focus of this review, but the potential variability of origin of multifocal glioblastoma will certainly be the focus of further research. Multifocal glioblastomas carry a poorer prognosis, as compared to focal, or lobar, glioblastoma [38,39]. As described earlier for deep seated glioblastoma, this may, in fact, be representative of a treatment bias, as the majority of multifocal glioblastomas will undergo biopsy rather than meaningful resection. Significant resection is a well-documented prognostic factor in glioblastoma [35].

Radiation is less effective for multifocal tumors, and in many centers is reluctantly used, due to the cognitive effects, which have been shown to be worse in treatment for multifocal disease. In many of these cases, in fact, Temozolomide is given as single treatment. Withdrawal of radiation may also contribute to the poor prognosis associated with multifocal glioblastoma [40,41]. As second line treatment, Bevacizumab is commonly given, but is also less efficacious in these tumors compared to focal glioblastoma $[42,43]$.

\section{Glioblastoma in single supratentorial lobes}

There is information in the literature regarding glioblastoma in specific lobes, including insights of lobe-specific presentation, lobectomy vs. resection and insular involvement [44-47]. However, there is no direct comparison of the outcomes of surgery, or other treatment modalities for glioblastoma in different lobes.

Even the relative incidence of glioblastoma in different lobes is unknown, and it is unclear whether this incidence correlates to the volume of the different lobes or not.

\section{Conclusion}

Both surgery and radiation are less effective in periventricular glioblastoma, perhaps owing to this area being the niche for pluripotent stem cells in glioblastoma. Surgery carries less of a survival benefit in deep seated glioblastoma, in part because gross total resection of these tumors is uncommonly reached. All treatment modalities are less efficacious for multifocal glioblastoma. There is not enough data in the literature about the prognosis and treatment of specific single lobe supratentorial glioblastoma.

\section{Acknowledgement}

None.

\section{Conflict of Interest}

No conflict of interest.

\section{References}

1. Tesileanu CMS, Dirven L, Wijnenga MMJ, Koekkoek JAF, Vincent AJPE, et al. (2019) Survival of diffuse astrocytic glioma, IDH1/2-wildtype, with molecular features of glioblastoma, WHO grade IV: a confirmation of the cIMPACT-NOW criteria. Neuro Oncol.

2. Bhavya B, Anand CR, Madhusoodanan UK, Rajalakshmi P, Krishnakumar $\mathrm{K}$, et al. (2019) To be Wild or Mutant: Role of Isocitrate Dehydrogenase 1 (IDH1) and 2-Hydroxy Glutarate (2-HG) in Gliomagenesis and Treatment Outcome in Glioma. Cell Mol Neurobiol.

3. Adilijiang A, Hirano M, Okuno Y, Aoki K, Ohka F, et al. (2019) Next Generation Sequencing-Based Transcriptome Predicts Bevacizumab Efficacy in Combination with Temozolomide in Glioblastoma. Molecules $24(17)$

4. Mathios D, Hwang T, Xia Y, Phallen J, Rui Y, et al. (2019) Genome-wide investigation of intragenic DNA methylation identifies ZMIZ1 gene as a prognostic marker in glioblastoma and multiple cancer types. Int J Cancer.145(12): 3425-3435.

5. Wang Q, Zhang J, Li F, Xu X, Xu B (2019) Diagnostic performance of clinical properties and conventional magnetic resonance imaging for determining the IDH1 mutation status in glioblastoma: a retrospective study. PeerJ 7: e7154.

6. Mirchia K, Sathe AA, Walker JM, Fudym Y, Galbraith K, et al. (2019) Total copy number variation as a prognostic factor in adult astrocytoma subtypes. Acta Neuropathol Commun 7(1): 92.

7. Hwang T, Mathios D, McDonald KL, Daris I, Park SH, et al. (2019) Integrative analysis of DNA methylation suggests down-regulation of oncogenic pathways and reduced somatic mutation rates in survival outliers of glioblastoma. Acta Neuropathol Commun 7(1): 88.

8. Yin AA, He YL, Etcheverry A, Liu YH, Aubry M, et al. (2019) Novel predictive epigenetic signature for temozolomide in non-G-CIMP glioblastomas. Clin Epigenetics 11(1): 76.

9. Richardson TE, Patel S, Serrano J, Sathe AA, Daoud EV, et al. (2019) Genome-Wide Analysis of Glioblastoma Patients with Unexpectedly Long Survival. J Neuropathol Exp Neurol 78(6): 501-507.

10. Paldor I, Drummond KJ, Kaye AH (2016) IDH1 mutation may not be prognostically favorable in glioblastoma when controlled for tumor location: A case-control study. J Clin Neurosci 34: 117-120.

11. Sasaki T, Kinoshita M, Fujita K, Fukai J, Hayashi N, et al. (2019) Radiomics and MGMT promoter methylation for prognostication of newly diagnosed glioblastoma. Sci Rep 9(1): 14435.

12. Wee CW, Kim E, Kim N, Kim IA, Kim TM, et al. (2017) Novel recursive partitioning analysis classification for newly diagnosed glioblastoma: A multi-institutional study highlighting the MGMT promoter methylation and IDH1 gene mutation status. Radiother Oncol 123(1): 106-111.

13. Nguyen HN, Lie A, Li T, Chowdhury R, Liu F, et al. (2017) Human TERT promoter mutation enables survival advantage from MGMT promoter methylation in IDH1 wild-type primary glioblastoma treated by standard chemoradiotherapy. Neuro Oncol 19(3): 394-404.

14. Boyrie S, Delmas C, Lemarié A, Lubrano V, Dahan P, et al. (2018) RND1 regulates migration of human glioblastoma stem-like cells according to their anatomical localization and defines a prognostic signature in glioblastoma. Oncotarget 9(73): 33788-33803.

15. Georgescu MM, Li Y, Islam MZ, Notarianni C, Sun H, etal. (2019) Mutations of the MAPK/TSC/mTOR pathway characterize periventricular glioblastoma with epithelioid SEGA-like morphology-morphological and therapeutic implications. Oncotarget 10(40): 4038-4052.

16. Quiñones Hinojosa A, Sanai N, Soriano Navarro M, Gonzalez Perez O, Mirzadeh Z, et al. (2006) Cellular composition and cytoarchitecture of the adult human subventricular zone: a niche of neural stem cells. J Comp Neurol 494(3): 415-434.

17. Shen Q, Wang Y, Kokovay E, Lin G, Chuang SM, et al. (2008) Adult SVZ stem cells lie in a vascular niche: a quantitative analysis of niche cell-cell interactions. Cell Stem Cell 3(3): 289-300. 
18. Justin D Lathia, Stephen C Mack, Erin E Mulkearns Hubert, Claudia LL Valentim, Jeremy N Rich (2015) Cancer stem cells in glioblastoma. Genes Dev 29(12): 1203-1217.

19. Ivy AW Ho, Winston SN (2017) Shim Contribution of the Microenvironmental Niche to Glioblastoma Heterogeneity. Biomed Res Int: 9634172.

20. Geoffrey S Young, Eric A Macklin, Kian Setayesh, Joshua D Lawson, Patrick Y Wen, et al. (2011) Longitudinal MRI evidence for decreased survival among periventricular glioblastoma. J Neurooncol 104(1): 261269.

21. Kaisorn L Chaichana, Courtney Pendleton, Lola Chambless, Joaquin Camara Quintana, Jay K Nathan, et al. (2013) Multi-institutional validation of a preoperative scoring system which predicts survival for patients with glioblastoma. J Clin Neurosci 20(10): 1422-1426.

22. Awad AW, Karsy M, Sanai N, Spetzler R, Zhang Y, et al. (2017) Impact of removed tumor volume and location on patient outcome in glioblastoma. J Neurooncol 135(1): 161-171.

23. John JK, Robin AM, Pabaney AH, Rammo RA, Schultz LR, et al. (2017) Complications of ventricular entry during craniotomy for brain tumor resection. J Neurosurg 127(2): 426-432.

24. Mistry AM, Dewan MC, White Dzuro GA, Brinson PR, Weaver KD, et al. (2017) Decreased survival in glioblastomas is specific to contact with the ventricular-subventricular zone, not subgranular zone or corpus callosum. J Neurooncol 132(2): 341-349.

25. Mistry AM, Hale AT, Chambless LB, Weaver KD, Thompson RC, et al. (2017) Influence of glioblastoma contact with the lateral ventricle on survival: a meta-analysis. J Neurooncol 131(1): 125-133

26. Yang W, Xu T, Garzon Muvdi T, Jiang C, Huang J, et al. (2018) Survival of Ventricular and Periventricular High-Grade Gliomas: A Surveillance, Epidemiology, and End Results Program-Based Study. World Neurosurg 111: e323-e334.

27. Valiyaveettil D, Malik M, Joseph DM (2019) Effect of radiation dose to the periventricular zone and subventricular zone on survival in anaplastic gliomas. Ecancermedicalscience 13: 956.

28. Esquenazi Y, Moussazadeh N, Link TW, Hovinga KE, Reiner AS, et al. (2018) Thalamic Glioblastoma: Clinical Presentation, Management Strategies, and Outcomes. Neurosurgery 83(1): 76-85.

29. Wu B, Tang C, Wang Y, Li Z, Hu S, et al. (2018) High-grade thalamic gliomas: Microsurgical treatment and prognosis analysis. J Clin Neurosci 49: 56-61.

30. Steiger HJ, Götz C, Schmid Elsaesser R, Stummer W (2000) Thalamic astrocytomas: surgical anatomy and results of a pilot series using maximum microsurgical removal. Acta Neurochir (Wien) 142(12): 1327-1336; discussion 1336-1337.

31. Nishio S, Morioka T, Suzuki S, Takeshita I, Fukui M (1997) Thalamic gliomas: a clinicopathologic analysis of 20 cases with reference to patient age. Acta Neurochir (Wien) 139(4): 336-342.

32. Paldor I, Pearce FC, Drummond KJ, Kaye AH (2016) Frontal glioblastoma multiforme may be biologically distinct from non-frontal and multilobar tumors. J Clin Neurosci 34: 128-132.

33. Briggs RG, Nix CE, Conner AK, Palejwala AH, Smitherman AD, et al. (2019) An Awake Contralateral, Transcallosal Approach for Deep-Seated Gliomas of the Basal Ganglia. World Neurosurg 130: e880-e887.
34. Lombardi G, Della Puppa A, Gardiman MP, Rossi S, Candiotto C, et al. (2018) Discordance of IDH mutational status between lesions in an adult patient with multifocal glioma. Neuro Oncol 20(8): 1142-1143.

35. Ahmadipour Y, Jabbarli R, Gembruch O, Pierscianek D, Darkwah Oppong M, et al. (2019) Impact of Multifocality and Molecular Markers on Survival of Glioblastoma. World Neurosurg 122: e461-e466.

36. Abou El Ardat K, Seifert M, Becker K, Eisenreich S, Lehmann M, et al. (2017) Comprehensive molecular characterization of multifocal glioblastoma proves its monoclonal origin and reveals novel insights into clonal evolution and heterogeneity of glioblastomas. Neuro Oncol 19(4): 546-557.

37. Liu Q, Liu Y, Li W, Wang X, Sawaya R, et al. (2015) Genetic, epigenetic, and molecular landscapes of multifocal and multicentric glioblastoma. Acta Neuropathol 130(4): 587-597.

38. Toh CH, Liau CT, Wei KC, Castillo M (2019) Baseline multicentric tumors, distant recurrences and leptomeningeal dissemination predict poor survival in patients with recurrent glioblastomas receiving bevacizumab. J Neurooncol 142(1): 149-159.

39. Jungk C, Warta R, Mock A, Friauf S, Hug B, et al (2019) LocationDependent Patient Outcome and Recurrence Patterns in IDH1-Wildtype Glioblastoma. Cancers (Basel) 11(1): 122.

40. Lahmi L, Idbaih A, Rivin Del Campo E, Hoang Xuan K, Mokhtari K, et al. (2019) Whole brain radiotherapy with concurrent temozolomide in multifocal and/or multicentric newly diagnosed glioblastoma. J Clin Neurosci 68: 39-44.

41. Ahmadipour Y, Kaur M, Pierscianek D, Gembruch O, Oppong MD, et al. (2019) Association of Surgical Resection, Disability, and Survival in Patients with Glioblastoma. J Neurol Surg A Cent Eur Neurosurg 80(4): 262-268.

42. Michael C Burger, Stella Breuer, Hans C Cieplik, Patrick N Harter, Kea Franz, et al. (2017) Bevacizumab for Patients with Recurrent Multifocal Glioblastomas. Int J Mol Sci 18(11): 2469

43. Darmon I, Morisse MC, Coutte A, Blonski M, Le Rhun E, et al. (2017) Temozolomide and Bevacizumab Induction before Chemoradiotherapy in Patients with Bulky Glioblastoma and/or with Severe Neurological Impairment. J Cancer 8(8): 1417-1424.

44. Jayamanne D, Wheeler H, Brazier D, Newey A, Kastelan M, et al. (2018) Predicting patterns of failure in temporal lobe GBMs: possible implications on radiotherapy treatment portals. Radiat Oncol 13(1): 133.

45. Roh TH, Kang SG, Moon JH, Sung KS, Park HH, et al. (2019) Survival benefit of lobectomy over gross-total resection without lobectomy in cases of glioblastoma in the noneloquent area: a retrospective study. J Neurosurg 1: 1-7.

46. Schneider M, Potthoff AL, Keil VC, Güresir Á, Weller J, et al. (2019) Surgery for temporal glioblastoma: lobectomy outranks oncosurgicalbased gross-total resection. J Neurooncol 145(1): 143-150.

47. Franssen A, Sienaert P (2019) Temporal glioblastoma presenting as catatonia. BMJ Case Rep 12(3). 